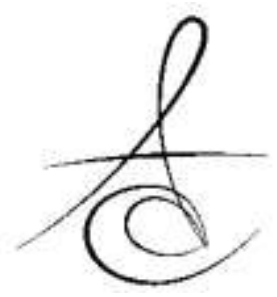

\section{ADEZIV UYGULAMA SÜRESİNİN UZATILMASININ MAKASLAMA BAĞLANMA DAYANIMI ÜZERİNE ETKİSİ}

\section{THE EFFECT OF PROLONGED APPLICATION TIME ON THE RESIN-DENTIN SHEAR BOND STRENGTH}

\author{
Arş. Gör. Dt. Buket KARALAR ${ }^{*} \quad$ Arş. Gör. Dt. Selin NACAK* \\ Doç. Dr. Nurcan ÖZAKAR İLDAY*
}

Buket Karalar: ORCID ID: 0000-0002-7855-1246

Selin Nacak: ORCID ID: 0000-0002-0641-6651

Nurcan Özakar İlday: ORCID ID: 0000-0003-4023-6723

\title{
Öz
}

Amaç: Bu çalışmanın amacl; üniversal adezivlerin uygulama zamanlarının uzatılmasının, makaslama bağlanma dayanımı üzerine etkisinin araştırılmasıdır.

Gereç ve Yöntem: Çalışmamızda 63 adet çürüksüz insan molar dişi kullanıldı. Okluzal kısımda yüzeyel dentin açığa çıkarıldıktan sonra; örnekler, rastgele, kullanılacak olan üç farklı adezivin farklı uygulama sürelerine göre ( $5 \mathrm{sn}, 10 \mathrm{sn}, 20 \mathrm{sn}) 9$ gruba ayrıldı $(n=7)$ (1. Single Bond Universal, 2. One Coat 7 Universal, 3. All-Bond Universal). X-trafil bulk-fill kompozit kullanılarak tek tabaka halinde $4 \mathrm{~mm}$ yüksekliğinde ve $3 \mathrm{~mm}$ çapında kalıplar yardımıyla restoratif kısım tamamlandı ve LED cihazıyla polimerize edildi. Örnekler 24 saat $37^{\circ} \mathrm{C}$ suda bekletilip üniversal test cihazına (Instron 3344, Instron Corp, Wilmington, ABD) yerleştirildi. Veriler ANOVA ve Duncan testleri ile 0.05 anlamllık düzeyinde analiz edildi.

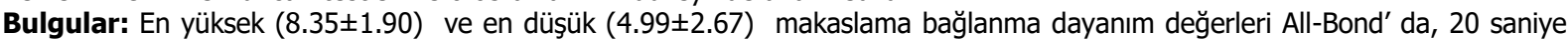
ve 10 saniye uygulama süreli gruplarda gözlenmiştir. All-Bond grubunda istatistiksel anlamda farklılık gözlenirken $(p<0.05)$, diğer gruplarda istatistiksel olarak anlamlı bir farklıık bulunamamışır $(p>0.05)$.

Sonuç: Uygulama süresinin arttırıması All-Bond grubunda makaslama bağlanma dayanımını anlamlı oranda yükseltmiştir $(p<0.05)$. Single Bond Universal ve One Coat 7 gruplarında ise istatistiksel olarak anlamlı bir farklılık görülmemiştir $(p>0.05)$. Anahtar Kelimeler: Dentin, Makaslama bağlanma dayanımı, Uygulama süresi, Üniversal adeziv

Aim: The aim of this study was to examine the effect of prolonged application time on the resin-dentin shear bond strength (SBS).

Materials And Methods: Caries-free sixty three human molars were used. After superficial dentin was exposed, samples were divided into nine groups ( $n=7)$ according to according to different application times ( $5 \mathrm{sec}, 10 \mathrm{sec}, 20 \mathrm{sec}$ ) of the three different adhesives (1. Single Bond Universal, 2. One Coat 7 Universal, 3. All-Bond Universal) Composite build-ups were made with Xtrafil bulk-fill composite with the help of $4 \mathrm{~mm}$ height and $3 \mathrm{~mm}$ diameter molds as a single layer and polymerized with a lightemitting diode (LED). After immersion in water at $37^{\circ} \mathrm{C}$ for $24 \mathrm{~h}$, the shear bond strength were measured by using with the universal testing machine (Instron 3344, Instron Corp, Wilmington, ABD). The results were analyzed statistically by using oneway ANOVA and Duncan's post-hoc analysis at a significance level of 0.05 .

Results: The highest and the lowest SBS values were observed in the All bond groups (8.35 \pm 1.90$)$ and (4.99 \pm 2.67$)$ applied $20 \mathrm{~s}$ and $10 \mathrm{~s}$. A statistically significant difference was observed between All-bond groups $(p<0.05)$. There was no significant difference in the other groups ( $p>0.05)$.

Conclusion: Increasing the application time significantly improved the bond strength of All-bond group; however, it had no significant effect on the bond strength of Single Bond Universal and One Coat 7 groups.

Keywords: Dentin, Shear bond strength, Application time, Universal adhesive

\footnotetext{
${ }^{*}$ Atatürk Üniversitesi, Diş Hekimliği Fakültesi, Restoratif Diş Tedavisi Anabilim Dall, Erzurum

¥ Çalışma Estetik Diş Hekimliği Akademisi Derneğinin (EDAD) 22. Uluslararası Bilimsel Kongresinde (19-21 Ekim 2018, İstanbul, Türkive) sözlü sunum olarak sunulmustur.
}

Kaynakça Bilgisi: Karalar B, Nacak S, Özakar İlday N. Adeziv Uygulama Süresinin Uzatılmasının Makaslama Bağlanma Dayanımı Üzerine Etkisi. Atatürk Üniv Diş Hek Fak Derg 2020; 30: 196-201.

Citation Information: Karalar B, Nacak S, Özakar İlday N. The Effect of Prolonged Application Time on the Resin-Dentin Shear Bond Strength. J Dent Fac Atatürk Uni 2020; 30: 196-201. 


\section{GİRİş}

Günümüzde hastaların estetik restorasyonlara olan taleplerinin artmasıyla daha konservatif kavite preperasyonları tercih edilmeye başlanmış ve bu sayede direkt kompozit rezin materyallerinin kullanımı oldukça yaygınlaşmıştır. Bir kompozit restorasyonın klinik başarısı, uygulanan adeziv sistemin başarısıyla doğrudan ilişkilidir. ${ }^{1}$ Dental adeziv sistemler, totaletch (pürüzlendirip yıkamalı) ve self-etch (kendinden pürüzlendirmeli) olmak üzere iki ana kategoride sınıflandırılmaktadır. Uygulama aşamalarına göre de bu sistemler tek basamaklı, iki ya da üç basamaklı olarak alt gruplara ayrımaktadırlar. ${ }^{2}$

Geçtiğimiz yıllarda hem etch\&rinse hem de selfetch teknikle beraber kullanılabilecek, 'üniversal' ya da 'multi-mod' olarak adlandırılan yeni bir tek aşamalı adeziv sistem grubu piyasaya sürülmüştür. ${ }^{3}$ Bu yeni sistem sayesinde hekim, tek bir bağlayıcı ajan ile hangi adeziv sistemi kullanacağına kendisi karar verme şansına sahip olmaktadır. ${ }^{4}$ Halen birçok üretici, adeziv uygulama prosedürlerini basitleştirmeye çalışmaktadır. All-in-one sistemler ve universal adezivlerin self-etch modunda kullanımı; etching, priming ve bonding aşamalarının tek bir adımda yapılabilmesine olanak sağlayarak, üç ve iki adımlı adeziv sistemlere göre uygulama süresini ve teknik duyarlıı̆ı azaltmıştır. Güncel araştırmalar adeziv sistemlerinin uygulama yöntemi ile ilgili olarak, aktif uygulamalarının (sürtünme hareketi ile) mine ${ }^{5}$ ve dentine $e^{6,7}$ bağlanma gücünü arttırdığını ortaya koymuştur.

Bazı yazarlar mine ve dentinde fosforik asitle aşındırma yapılmadan tek aşamalı adeziv uygulamasının başarılı olabilmesi için uygulanan adeziv tabakasının ya da uygulama süresinin arttırıması gerektiğini savunmuşlardır. ${ }^{8-12}$ Uzun uygulama süreleri altında oluşan rezin-dentin arayüzleri, muhtemelen hibrit tabaka içinde daha kararlı bir polimer oluşumu nedeniyle zaman içinde daha kararlı hale gelmektedir. Bu nedenle bağlayıcı ajanların uygulama sürelerindeki artışın, dentin bağlarııı ömrünü uzatmak için klinik bir alternatif olabileceği düşünülmüştür. ${ }^{13}$ Buna karşın adezivlerin uygulama süresinin uzatılmasının bağlanma dayanımı üzerine etkisinin araştıııdığı çalışma sayısı oldukça azdır. ${ }^{14-17}$

$\mathrm{Bu}$ in vitro çalışmanın amacl; üniversal adezivlerin uygulama zamanlarının uzatımasının, makaslama bağlanma dayanımı üzerine etkisinin araştırımasıdır. Çalışmamızın sıfır hipotezi; adeziv uygulama süresinin uzatılmasının makaslama bağlanma dayanımına etkisi olmadığı şeklindedir.

\section{MATERYAL ve METOD}

Bu çalışma, Atatürk Üniversitesi Diş Hekimliği Fakültesi Dekanlığı Etik Kurulu'nun onayı alınarak $(8 ; 18.09 .2018)$ yürütülmüştür.

Çalışmada kullanılmak üzere yeni çekilmiş veya çekildikten sonra en fazla 6 ay beklemiş olan çürüksüz insan molar dişleri seçildi. Çekimi takiben dişler üzerindeki doku artıkları ve eklentiler akan su altında kretuvar ve fırça yardımıyla temizlendi. Dişler toplandıktan sonra $+4^{\circ} \mathrm{C}^{\prime}$ de $\%$ 0,5'lik kloramin-T solüsyonu içinde 6 ay boyunca karanlık ortamda saklandı.

Çalışmamızda periodontal sebeplerle çekilmiş, yüzeyinde kırı veya çürük bulunmayan 63 adet insan molar dişi kullanıldı. Gözle görülür defekti olan dişler çalışmaya dahil edilmedi. Dişlerin üzerindeki eklentiler periodontal küret yardımıyla uzaklaştııılıktan sonra kuron kısmı dışarıda kalacak şekilde akrilik kalıplara gömüldü.

Dişlerin okluzal yüzeylerindeki mine dokusu yavaş hızla çalışan testere (Isomet Low Speed Saw 1000; Buehler, Lake Buff, IL, ABD) kullanılarak uzaklaştııldı. Standart bir smear tabakası elde edebilmek için tüm örneklerin oklüzal yüzeyleri 600 grit silikon karbit zımpara kullanılarak 60 sn boyunca sürekli su soğutması altında zımparalandı ve adezivin bağlanmasına hazır hale getirildi.

Örnekler, tamamen rastgele olarak, kullanilacak olan adeziv materyallere ve uygulama sürelerine göre dokuz gruba ayrıldı. $(n=7)$ (Tablo 1$)$

Gruplamadan sonra bağlayıc ajanlar 5 sn, 10 sn, 20 sn sürelerle dentin yüzeyine aktif bir şekilde ovalayarak uygulandı ve LED cihazı (Woodpecker LED. D, Guilin Woodpecker Medical Instrument Co. Guanzgxi, Çin $850 \mathrm{~mW} / \mathrm{cm}^{2}$ ) kullanılarak $10 \mathrm{sn}$ boyunca polimerize edildi.

Daha sonra örneklerin restoratif kısmı, $3 \mathrm{~mm}$ çapında $4 \mathrm{~mm}$ yüksekliğinde silindirik şekilli plastik kalıplar yardımıyla X-trafil bulk-fill kompozit (Voco, Cuxhaven, Almanya LOT:1748081) kullanilarak tamamlandı. Kompozit rezinler LED cihazıyla üretici firmanın talimatları doğrultusunda 10 sn boyunca polimerize edildi. 
Tablo 1. Kullanılan adeziv sistemlerin içerikleri, üretici firma ve uygulama süreleri

\begin{tabular}{|c|c|c|c|c|c|}
\hline $\begin{array}{l}\text { ADEZİV } \\
\text { SİSTEM }\end{array}$ & İÇERİK & $\begin{array}{l}\text { ÜRETÍCI } \\
\text { FİRMA / }\end{array}$ & \multicolumn{3}{|c|}{$\begin{array}{l}\text { UYGULAMA } \\
\text { SÜRESİ }\end{array}$} \\
\hline $\begin{array}{l}\text { Single } \\
\text { Bond } \\
\text { Universal }\end{array}$ & $\begin{array}{c}\text { 10-MDP, } \\
\text { dimetakrilat } \\
\text { rezinler, BIS-GMA, } \\
\text { HEMA, } \\
\text { metakrilatmodifiye } \\
\text { polialkenoik asit } \\
\text { kopolimeri, } \\
\text { doldurucu, etanol, } \\
\text { su, initiatörler, } \\
\text { silan }\end{array}$ & $\begin{array}{c}\text { 3M ESPE, } \\
\text { St. Paul, MN, } \\
\text { ABD } \\
\text { LOT: } \\
3767361\end{array}$ & $5 \mathrm{sn}$ & $10 \mathrm{sn}$ & $20 \mathrm{sn}$ \\
\hline $\begin{array}{c}\text { One Coat } \\
7 \\
\text { Universal }\end{array}$ & $\begin{array}{l}\text { 10-MDP, HEMA, } \\
\text { UDMA, } \\
\text { metakrilatlı } \\
\text { poliakrilik asit, } \\
\text { diğer } \\
\text { metakrilatlar, } \\
\text { photoinitiatorler, } \\
\text { etanol, su }\end{array}$ & $\begin{array}{l}\text { Coltène } \\
\text { Whaledent, } \\
\text { Altstätten, } \\
\text { İsviçre } \\
\text { LOT: I28740 }\end{array}$ & $5 \mathrm{sn}$ & $10 \mathrm{sn}$ & $20 \mathrm{sn}$ \\
\hline $\begin{array}{l}\text { All-Bond } \\
\text { Universal }\end{array}$ & $\begin{array}{l}\text { 10-MDP, Bis-GMA, } \\
\text { HEMA, etanol, su, } \\
\text { initiatörler }\end{array}$ & $\begin{array}{c}\text { Bisco, Inc. } \\
\text { Schaumburg, } \\
\text { ABD } \\
\text { LOT: } \\
\text { 1700000797 }\end{array}$ & $5 \mathrm{sn}$ & $10 \mathrm{sn}$ & $20 \mathrm{sn}$ \\
\hline
\end{tabular}

Örnekler 24 saat boyunca $37^{\circ} \mathrm{C}$ suda bekletildi ve özel bir tutucu parça vasıtası ile üniversal bir test cihazına (Instron 3344, Instron Corp, Wilmington, $A B D)$ yerleştirildi. Özel bir uç yardımı ile dentinkompozit bağlanma alanına, kopma oluncaya kadar kuvvet uygulandı (1 $\mathrm{mm} / \mathrm{dk})$. Restoratif materyalin kırıma anındaki en yüksek makaslama bağlanma dayanım değerleri not edildi. Kaydedilen veriler tek yönlü ANOVA ve Duncan çoklu karşılaştırma testleri ile analiz edildi. $p<0.05$ değeri istatistiksel olarak anlamlı kabul edildi.

\section{BULGULAR}

Örneklerin makaslama bağlanma dayanımı değerleri ve standart sapmaları Tablo 2'de verilmiştir. En yüksek makaslama bağlanma dayanımı değerleri All Bond Universal 20 sn uygulama süreli grupta $(8.35 \pm 1.90 \mathrm{MPa})$, en düşük makaslama bağlanma dayanımı değerleri All Bond Universal $10 \mathrm{sn}$ uygulama süreli grupta $(4.99 \pm 2.67 \mathrm{MPa})$ gözlenmiştir. All-Bond Universal grupları arasında istatistiksel anlamda farkllık gözlenirken $(p<0.05)$, diğer gruplarda istatistiksel olarak anlamlı bir farkllık bulunamamıştır ( $p>0.05)$.
Tablo 2. Grupların ortalama bağlanma ve standart sapma değerleri (MPa)

\begin{tabular}{|c|c|c|c|}
\hline \multirow[b]{2}{*}{$\begin{array}{c}\text { ADEZIV } \\
\text { SİSTEMLER }\end{array}$} & \multicolumn{3}{|c|}{$\begin{array}{c}\text { Ortalama Makaslama Bağlanma Dayanımı } \\
\text { Değerleri (MPa) }\end{array}$} \\
\hline & $\frac{\begin{array}{c}5 \text { sn } \\
\text { uygulama }\end{array}}{(n=7)}$ & $\frac{\begin{array}{c}10 \mathrm{sn} \\
\text { uygulama }\end{array}}{(n=7)}$ & $\frac{\begin{array}{c}20 \text { sn } \\
\text { uygulama }\end{array}}{(n=7)}$ \\
\hline $\begin{array}{l}\text { Single Bond } \\
\text { Universal }\end{array}$ & $5.67 \pm 2.38^{\mathrm{A}, \mathrm{a}}$ & $5.59 \pm 2.13^{\mathrm{A}, \mathrm{a}}$ & $7.47 \pm 2.62^{\mathrm{A}, \mathrm{a}}$ \\
\hline $\begin{array}{l}\text { One Coat } 7 \\
\text { Universal }\end{array}$ & $6.61 \pm 2.51^{\mathrm{A}, \mathrm{a}}$ & $6.89 \pm 1.75^{\mathrm{A}, \mathrm{a}}$ & $6.41 \pm 3.22^{\mathrm{A}, \mathrm{a}}$ \\
\hline $\begin{array}{l}\text { All-Bond } \\
\text { Universal }\end{array}$ & $6.18 \pm 2.11^{A B, a}$ & $4.99 \pm 2.67^{\mathrm{B}, \mathrm{a}}$ & $8.35 \pm 1.90^{\mathrm{A}, \mathrm{a}}$ \\
\hline
\end{tabular}

\section{TARTIŞMA}

Dentin dokusunun nemli ve karmaşık yapısı nedeniyle bağlanma mine dokusuna nazaran daha zordur ve adeziv sistem uygulanırken daha fazla dikkat gerektirmektedir. ${ }^{18}$ Yapılan çalışmalarda yüzeyel dentin bölgelerinde oluşan bağlanma kuvvetlerinin, derin dentin bölgesine göre daha fazla olduğu bildirilmiştir. ${ }^{19,} 20$ Bu sebeple çalışmamızda yüzeyel dentine olan makaslama bağlanma dayanım değerleri test edilmiştir.

İn vivo şartlarda restoratif materyallerin adezyonlarının bozulması ve bağlantı problemlerinin oluşmasına en fazla makaslama gerilimlerinin neden olduğu düşünülmektedir. Bu nedenle klinik performanslarının tahmin edilebilmesinde ve laboratuvar ortamında en sık tercih edilen test metodu olan makaslama bağlanma dayanım testi önerilmiştir. ${ }^{2,21}$

Üniversal adeziv sistemler dental marketlerde yer alan en yeni bağlayııı ajan grubudur. Klinik olarak kullanım kolaylığı sağlayan self-etch adezivlerde olduğu gibi 'All-in-one' konsepti ile tasarlanılmıştır. Aynı zamanda çok amaçlı kullanımları mümkün olduğundan, fosforik asitle beraber (selektif etch ve etch-and-rinse) veya sadece self-etch olarak kullanılabilmektedirler. ${ }^{22}$

Üretici firma talimatlarına göre uygulanan adeziv içeriğindeki monomerlerin, demineralize kollajen ağı arasına homojen bir şekilde nüfuz edemediği bildirilmiştir. ${ }^{23,}{ }^{24}$ Rezin monomerlerinin yaklaşık \% 98'inin rezin-dentin arayüzünün ilk mikrometresine nüfuz edebileceği gösterilmiş̧ir. Bu penetrasyon, ikinci mikrometrede \% 89'a, üçüncü mikrometrede \% 71'e düşmektedir ve demineralize dentin derinliğinde BisGMA/HEMA rezin monomerlerinin sadece $\% 18^{\prime} \mathrm{i}$ bulunmaktadır. ${ }^{24}$ Bağlanmış arayüz içindeki demineralize dentin bölgesinin ortadan kaldırıması ya da azaltıl-

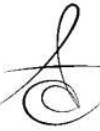


masına yönelik yapılan işlemler, korunmasız kollajen fibrillerinin sayısını azaltabilir, buna bağlı olarak da kompozit restorasyonların kullanım ömrü artabilir. Hibrit tabaka oluşumu ve derinliği de, bağlayıcı ajanların uygulama sürelerine bağlı olarak değişebilir. Bununla birlikte, daha kalın bir hibrid tabaka, uzun süreli uygulama sürelerinden sonra bağlanma dayanımı değerlerindeki artışı açıklayamayabilir. ${ }^{25} \mathrm{Bu}$ bilgilerin öncülüğünde, üniversal adezivlerin uygulama sürelerinin uzatılmasının monomer penetrasyonuna olumlu etkisinin olabileceği ve bağlanma dayanımını arttırabileceği düşünülerek çalışmamız planlandı.

Yapılan çalışmalarda, rezin infiltre olmuş tabakanın kalınlığı ile bağlanma dayanımı değerleri arasında herhangi bir korelasyon olmadığı bildirilmiştir. Bununla birlikte hibrit tabakanın kalınlığı yerine kalitesinin bağlanma dayanımı değerleri için daha önemli olduğu belirtilmiştir. ${ }^{25,} 26$

Önceki çalışmalar, bağlayıcı tabakanın özelliklerinin, dentin bağı mukavemeti için büyük önem taşıdığını bildirmiştir. 27-29 Adezivlerin bağlanma kuvvetinin, çözücü buharlaşma hızı ${ }^{30}$ ve bağlanma dayanımı değerleri ${ }^{31}$ ile pozitif olarak ilişkili olduğu bilinmektedir. Bu nedenle, bağlayıcı ajanların uzun süreli uygulamalarında, rezin-dentin arayüzünde daha güçlü polimer oluşumuna izin verecek şekilde daha fazla miktarda çözücü buharlaşabilir.

Uzun uygulama sürelerinde hem su/ethanol bazlı sistemler için hem de aseton bazlı sistemler için bağlanma kuvvetlerinde bir artış gözlense de, su/etanol bazlı sistemin daha yüksek bağlanma dayanımı değerleri elde etmek için aseton bazlı sistemden daha uzun bir uygulama süresi gerektirdiği yapılan çalışmalarda bildirilmiştir. ${ }^{32,} 33$

Türk ve arkadaşları ${ }^{14}$ yaptıkları bir çalışmada üç farklı üniversal adeziv sistemin (Single Bond Universal, 20 sn uygulama; G-aenial Bond,10 sn uygulama; Clearfil Universal Bond, 10 sn uygulama) makaslama bağlanma dayanım değerlerini kıyaslamışlar ve istatistiksel olarak anlamlı bir farklılık bulamamışlardır. Ancak Single bond Universal grubunun sayısal olarak diğer gruplara göre daha yüksek bir ortalamaya sahip olduğunu bildirmişlerdir. Cardenas ve arkadaşları ${ }^{16}$ üç farklı universal adeziv sistem (Clearfil Universal Bond, Futurabond Universal, Single Bond Universal) kullanarak yaptıkları bir çalışmada, 40 sn uygulama süreli grubun 20 sn uygulama süreli gruplara oranla daha yüksek bağlanma dayanım değerlerine sahip olduğunu tespit etmişlerdir.
Reis ve arkadaşları ${ }^{13}$, yaptıkları çalışmada iki farklı adeziv sistemi (Single Bond ve One Step) 40sn, $90 \mathrm{sn}, 150$ sn ve 300 sn boyunca uygulamışlar. 90 ve 150 saniye uygulamalı One Step gruplarının, 40 saniyelik gruptan belirgin bir şekilde daha yüksek bağlanma dayanımı değerlerine sahip olduğu tespit edilmiştir. Single Bond Universal'in bağlanma dayanımı değerlerinde sayısal bir artış olmasına rağmen 90 ve 150 saniyeli gruplar, 40 saniyeli gruba göre istatistiksel olarak anlamlı bir fark oluşturmamıştır.

Bizim çalışmamızda da kullanılan bağlayıcı ajanların klinik uygulama sürelerini uzatmamıza rağmen gruplar arasında istatistiksel olarak anlamlı bir farklılık bulunamamıştır $(p>0.05)$. Çalışmamızın bulguları doğrultusunda sıfır hipotezi kabul edilmiştir.

Tek basamaklı adeziv sistemler hidrofilik özelliklerinin fazla oluşu nedeniyle dentinle etkileşime girebilirler. Bu durum suya karşı geçirgen bir adeziv tabaka oluşturarak bağlayıcı ajanların adeziv performansını olumsuz yönde etkileyebilir. Bu problemin üstesinden gelmek için, All-Bond Universal minimum miktarda etanol ve su içerir. ${ }^{34}$ All-Bond Universal grubunda uygulama süresinin artışına bağlı olarak bağlanmanın artmasının All-Bond Universalin kimyasal içeriğindeki farklılıktan kaynaklanabileceğini düşünmekteyiz.

\section{SONUÇ}

Çalışmamızda klinik açıdan önem gösteren uygulama süreleri göz önüne alındığında; sürenin arttırıması All-Bond Universal adeziv grubunda makaslama bağlanma dayanımı değerlerini anlamlı oranda yükseltmiştir $(p<0.05)$. Single Bond Universal ve One Coat 7 Universal adeziv gruplarında ise istatistiksel olarak anlamlı bir farklılık bulunamamıştır ( $p>0.05)$.

Adeziv sistemlerin uygulama süreleri üretici firmalara göre değişmekle birlikte yapılan restorasyonlarda uzun dönem başarı elde edilebilmesi için ideal sürenin belirlenmesi oldukça önemlidir. Üniversal adezivlerin uygulama sürelerinin makaslama bağlanma dayanımına etkisinin tam olarak ortaya konulabilmesi için konu hakkında daha fazla çalışma yapılmasına ihtiyaç duyulmaktadır.

NOT: Calışmada herhangi bir yazar, kurum ya da kuruluş ile çıkar çatışması içerisinde bulunmamaktadır. Makale daha önce hiçbir yerde yayınlanmamış ve yayınlanmak üzere işlem görmemektedir 


\section{KAYNAKLAR}

1. Breschi L, Mazzoni A, Ruggeri A, Cadenaro M, Di Lenarda $R$, De Stefano Dorigo E. Dental adhesion review: aging and stability of the bonded interface. Dent Mater 2008; 24: 90-101.

2. De Munck J, Van Landuyt $K$, Peumans $M$, Poitevin A, Lambrechts P, Braem M, Van Meerbeek B. A critical review of the durability of adhesion to tooth tissue: methods and results. J Dent Res 2005; 84: 118-32.

3. Hanabusa $M$, Mine A, Kuboki T, Momoi $Y$, Van Ende A, Van Meerbeek B, De Munck J. Bonding effectiveness of a new 'multi-mode' adhesive to enamel and dentine. J Dent 2012; 40: 475-84.

4. Karadaş M, Hatipoğlu Ö, Ateş SM. Üniversal Adezivlerin Mineye Bağlanma Dayanımının Değerlendirilmesi. Atatürk Üniv Diş Hek Fak Derg 2018; 28: 204-9.

5. Caneppele TM, Torres CR, Sassaki A, Valdetaro F, Fernandes RS, Prieto de Freitas C, Batista GR. Effects of surface hydration state and application method on the bond strength of self-etching adhesives to cut enamel. J Adhes Dent 2012; 14: 25-30.

6. Do Amaral RC, Stanislawczuk R, Zander-Grande C, Michel MD, Reis A, Loguercio AD. Active application improves the bonding performance of self-etch adhesives to dentin. J Dent 2009; 37: 8290.

7. Gokce K, Aykor A, Ersoy M, Ozel E, Soyman M. Effect of phosphoric acid etching and self-etching primer application methods on dentinal shear bond strength. J Adhes Dent, 2008, 10: 345-49.

8. Strydom C. Self-etching adhesives: review of adhesion to tooth structure part I. SADJ 2004; 59: 413, 415-7, 419.

9. Perdigao J, Gomes G, Lopes MM. Influence of conditioning time on enamel adhesion. Quintessence Int 2006; 37: 35-41.

10. Velasquez LM, Sergent RS, Burgess JO, Mercante DE. Effect of placement agitation and placement time on the shear bond strength of 3 self-etching adhesives. Oper Dent 2006; 31: 426-30.

11. Kimmes NS, Barkmeier WW, Erickson RL, Latta MA. Adhesive bond strengths to enamel and dentin using recommended and extended treatment times. Oper Dent 2010; 35: 112-9.
12. Tsuchiya H, Tsubota $K$, Iwasa M, Ando S, Miyazaki $M$, Platt JA. Influence of adhesive application time on enamel bond strength of single-step self-etch adhesive systems. Oper Dent 2010; 35: 77-83.

13. Reis A, de Carvalho Cardoso P, Vieira LC, Baratieri $\mathrm{LN}$, Grande RH, Loguercio AD. Effect of prolonged application times on the durability of resin-dentin bonds. Dent Mater 2008; 24: 639-44.

14. Türk GI, Kara E. Üç farklı universal adeziv sistemin dentine makaslama bağlanma dayanımlarının karşılaştırılması. Selcuk Dental Journal, 2.2: 51-57.

15. Botelho MPJ, Isolan CP, Schwantz JK, Lopes MB, Moraes RR. Rubbing time and bonding performance of one-step adhesives to primary enamel and dentin. J Appl Oral Sci 2017; 25: 52332.

16. Cardenas AM, Siqueira F, Rocha J, Szesz AL, Anwar $M$, El-Askary $F$, Reis A, Loguercio A. Influence of Conditioning Time of Universal Adhesives on Adhesive Properties and Enamel-Etching Pattern. Oper Dent 2016; 41: 481-90.

17. Karaman E, Tuncer D, Karahan S, Ertan A. Farklı adeziv sistemlerin dentine makaslama bağlanma dayanımı: in vitro çalışma. Acta Odontologica Turcica 2015; 32: 112-5.

18. Itthagarun A, Tay FR. Self-contamination of deep dentin by dentin fluid. Am J Dent 2000; 13: 195200.

19. Marshall GW, Jr., Marshall SJ, Kinney JH, Balooch M. The dentin substrate: structure and properties related to bonding. J Dent 1997; 25: 441-58.

20. Pashley D, Okabe A, Parham P. The relationship between dentin microhardness and tubule density. Endod Dent Traumatol 1985; 1: 176-79.

21. Moll K, Fritzenschaft A, Haller B. In vitro comparison of dentin bonding systems: effect of testing method and operator. Quintessence Int 2004; 35: 845-52.

22. Wagner A, Wendler $M$, Petschelt A, Belli R, Lohbauer $U$. Bonding performance of universal adhesives in different etching modes. J Dent 2014; 42: 800-7.

23. Spencer $P$, Swafford JR. Unprotected protein at the dentin-adhesive interface. Quintessence Int 1999; 30: 501-7.

24. Wang Y, Spencer P. Hybridization efficiency of the adhesive/dentin interface with wet bonding. J Dent Res 2003; 82: 141-5. 
25. Nakabayashi N, Saimi Y. Bonding to intact dentin. J Dent Res 1996; 75: 1706-15.

26. Perdigao J, May KN, Jr., Wilder AD, Jr., Lopes $M$. The effect of depth of dentin demineralization on bond strengths and morphology of the hybrid layer. Oper Dent 2000; 25: 186-94.

27. Takahashi A, Sato Y, Uno S, Pereira PN, Sano H. Effects of mechanical properties of adhesive resins on bond strength to dentin. Dent Mater 2002; 18: 263-8.

28. Reis A, Grandi V, Carlotto L, Bortoli G, Patzlaff R, Rodrigues Accorinte Mde L, Dourado Loguercio A. Effect of smear layer thickness and acidity of selfetching solutions on early and long-term bond strength to dentin. J Dent, 2005, 33: 549-59.

29. Bae JH, Cho BH, Kim JS, Kim MS, Lee IB, Son HH, Um CM, Kim CK, Kim OY. Adhesive layer properties as a determinant of dentin bond strength. J Biomed Mater Res B Appl Biomater 2005; 74: 8228.

30. Ikeda T, De Munck J, Shirai K, Hikita K, Inoue S, Sano H, Lambrechts P, Van Meerbeek B. Effect of evaporation of primer components on ultimate tensile strengths of primer-adhesive mixture. J Dent Mater 2005; 21: 1051-8.

31. De Carvalho Cardoso P, Loguercio AD, Vieira LCC, Baratieri LN, Reis A. Effect of prolonged application times on resin-dentin bond strengths. J Adhes Dent 2005; 7: 143-9.

32. Abate P, Rodriguez V, Macchi R. Evaporation of solvent in one-bottle adhesives. J Dent 2000; 28: 437-40.

33. Pashley EL, Zhang Y, Lockwood PE, Rueggeberg FA, Pashley DH. Effects of HEMA on water evaporation from water-HEMA mixtures. Dent Mater 1998; 14: 6-10.

34. Sofan E, Sofan A, Palaia G, Tenore G, Romeo U, Migliau G. Classification review of dental adhesive systems: from the IV generation to the universal type. Ann Stomatol (Roma) 2017; 8: 1-17.

\section{Yazışma Adresi}

Arş. Gör. Dt. Buket Karalar

Atatürk Üniversitesi Diş Hekimliği Fakültesi, Restoratif Diş Tedavisi Anabilim Dalı, 25240, Erzurum, Türkiye

Tel: 04422311793

e-mail: bkt_ddk@hotmail.com 